\title{
Aetiology
}

\section{Patients with carotid artery stenosis had a high risk for stroke, and some types of stroke were not prevented by endarterectomy}

Barnett HJ, Gunton RW,Eliasziw M, et al. Causes and severity of ischemic stroke in patients with internal carotid artery stenosis.JAMA 2000 Mar 15;283:1429-36.

QUESTION: In patients with internal carotid artery (ICA) stenosis, what are the causes and severity of stroke for varying degrees of stenosis?

\section{Design}

Cohort study using data from the North American Symptomatic Carotid Endarterectomy Trial (NASCET) with mean follow up of 5 years.

\section{Setting}

106 centres mostly in North America.

\section{Patients}

2885 patients (median age 67 y, 70\% men) with ICA stenosis.

\section{Assessment of risk factors}

ICA stenosis measured by angiography and duplex ultrasonography; categories of stenosis were $<60 \%$, $60 \%$ to $69 \%$, and $70 \%$ to $99 \%$.

\section{Main outcome measures}

Ischaemic strokes were classified as large artery, lacunar, or cardioembolic (possible or probable) strokes. Severity was also assessed (non-disabling, disabling, or fatal).

\section{Main results}

During follow up, 749 patients had 1039 strokes: 67\% were large artery strokes, $20 \%$ were lacunar strokes, $11 \%$ were of cardioembolic origin, and $2 \%$ were intracerebral or subarachnoid haemorrhages. The 5 year risk of stroke was $20 \%$ for large artery stroke, $7 \%$ for lacunar stroke, and 3\% for cardioembolic stroke. The risk of large artery stroke increased with increasing stenosis; other categories of stroke were not related to degree of stenosis (table). The proportion of disabling or fatal strokes was $68 \%$ in cardioembolic stroke, $17 \%$ in lacunar stroke, and 33\% in large artery stroke.

\section{Conclusion}

A high proportion of patients with symptomatic and asymptomatic carotid artery stenosis had cardioembolic and lacunar strokes as well as large artery stroke.

Kaplan-Meier risks for cause specific stroke at 5 years for patients with carotid artery stenosis

\begin{tabular}{|c|c|c|c|}
\hline Disorder & $\begin{array}{l}\text { Stenosis } \\
<60 \%\end{array}$ & $\begin{array}{l}\text { Stenosis } \\
60 \% \text { to } 69 \%\end{array}$ & $\begin{array}{l}\text { Stenosis } \\
70 \% \text { to } 99 \%\end{array}$ \\
\hline \multicolumn{4}{|l|}{ Symptomatic stenosis } \\
\hline Large artery stroke & $11.8 \%$ & $17.3 \%$ & $25.4 \%$ \\
\hline Lacunar stroke & $5.8 \%$ & $6.8 \%$ & $4.5 \%$ \\
\hline Cardioembolic stroke & $1.6 \%$ & $3.5 \%$ & $1.2 \%$ \\
\hline \multicolumn{4}{|l|}{ Asymptomatic stenosis } \\
\hline Large artery stroke & $5.4 \%$ & $9.8 \%$ & $10 \%$ \\
\hline Lacunar stroke & $1.9 \%$ & $4.1 \%$ & $7.2 \%$ \\
\hline Cardioembolic stroke & $1.2 \%$ & $3.5 \%$ & $1.2 \%$ \\
\hline
\end{tabular}

Source of funding: National Institute of Neurological Disorders and Stroke.

For correspondence: Dr H J Barnett, John P Robarts Research Institute, $P O B$ Box 5015, 100 Perth Drive London, Ontario N6A 5 K8, Canada. Fax +1 5196633789

\section{COMMENTARY}

The study by Barnett $e$ al describes for the first time the long term outcome, in terms of the risk for and cause of subsequent stroke, of 2885 patients with ICA stenosis who were enrolled in a clinical trial of carotid endarterectomy (CE). As expected, these patients had a high rate (20\%) of subsequent large artery ischaemic stroke after 5 years, despite half having had treatment with $\mathrm{CE}$.

Perhaps less expected, another 10\% had a stroke caused by another disease, such as small vessel disease (7\%) or embolism from the heart (3\%). These results highlight the fact that among patients with severe carotid stenosis, whether symptomatic or asymptomatic, a large minority of subsequent strokes are caused by diseases other than carotid stenosis that are unlikely to be prevented by CE. The results also explain why CE reduces the relative risk for stroke by "only" half: CE prevents most or all subsequent ipsilateral strokes caused by large artery disease, but it does not prevent the other half of strokes that are caused by contralateral carotid stenosis, intracranial small vessel disease, and embolism from the heart.

The benefit of $\mathrm{CE}$ in a patient with severe carotid stenosis depends on his or her absolute risk for subsequent ipsilateral large artery ischaemic stroke (which $\mathrm{CE}$ can prevent) and the risk for perioperative stroke or death (which CE can cause). Only a few patients with severe carotid stenosis ultimately benefit from $\mathrm{CE}-$ mainly men with recent non-disabling carotid ischaemic events of the brain (as opposed to the eye) who have severe carotid stenosis ( $>70 \%$ using the NASCET criteria), carotid plaque irregularity, systolic blood pressure $<180 \mathrm{~mm} \mathrm{Hg}$, and no evidence of peripheral vascular disease. ${ }^{1}$ 